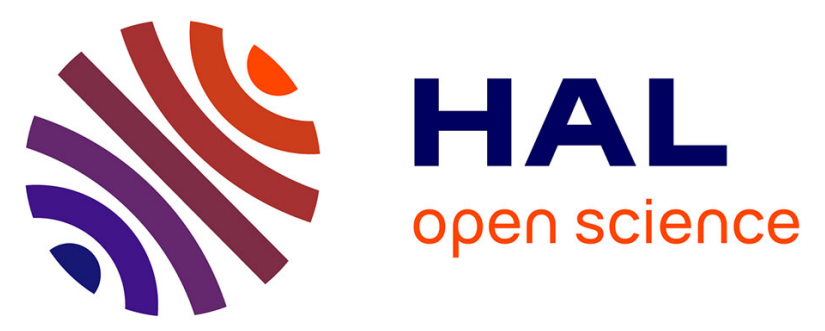

\title{
Toward an intelligent system architecture for smart agriculture: application to smart beehives
}

Jean-Charles Huet, Lamine Bougueroua, Yassine Kriouile, Alain Moretto

\section{To cite this version:}

Jean-Charles Huet, Lamine Bougueroua, Yassine Kriouile, Alain Moretto. Toward an intelligent system architecture for smart agriculture: application to smart beehives. The International Conference on Intelligent Systems Design and Applications (ISDA), Dec 2020, WWW, France. hal-03105207

\section{HAL Id: hal-03105207 \\ https://hal-mines-paristech.archives-ouvertes.fr/hal-03105207}

Submitted on 10 Jan 2021

HAL is a multi-disciplinary open access archive for the deposit and dissemination of scientific research documents, whether they are published or not. The documents may come from teaching and research institutions in France or abroad, or from public or private research centers.
L'archive ouverte pluridisciplinaire HAL, est destinée au dépôt et à la diffusion de documents scientifiques de niveau recherche, publiés ou non, émanant des établissements d'enseignement et de recherche français ou étrangers, des laboratoires publics ou privés. 


\title{
Toward an intelligent system architecture for smart agriculture: application to smart beehives ${ }^{\star}$
}

\author{
Jean-Charles Huet ${ }^{1}$, Lamine Bougueroua ${ }^{1}$, Yassine Kriouile ${ }^{1,2}$, and Alain \\ Moretto $^{3}$ \\ 1 AlliansTIC, EFREI Paris \\ 30/32 Avenue de la République, 94800 Villejuif, France \\ \{jean-charles.huet, Lamine.bougueroua\}@efrei.fr \\ 2 MINES ParisTech, PSL University, Centre de recherche en informatique \\ 35 rue Saint Honoré, 77300 Fontainbleau , France \\ yassine.kriouile@mines-paritech.fr \\ 3 ESITC Caen \\ 1 rue Pierre et Marie Curie, 14610 Epron, France
}

\begin{abstract}
Since the application of information and communications technologies (ICT) to agriculture is far from the potential, we investigate how to systematize the process of transformation. In this article, we propose a new approach to design intelligent systems for the management and supervision of smart agriculture, as well as an example of its application in the beekeeping sector. It consists of the analysis of all the decisions that can be made using a spatio-temporal matrix that couples the time horizons to the modeling approaches. The final goal is to develop a reusable architecture for smart agriculture.
\end{abstract}

Keywords: Intelligent system $\cdot$ architecture $\cdot$ smart agriculture $\cdot$ smart Beekeeping.

\section{Introduction}

Many applications in manufacturing systems require a combination of new technologies, which is giving rise to the emergence of Industry 4.0. The main technologies used by Industry 4.0 are Cyber-Physical Systems (CPS), IoT, Big Data, Cloud Computing...

CPS is mechanisms that allow monitoring using communication, data storage and computational capabilities directly incorporated into objects [3]. In fact, embedded software in CPS uses sensors and actuators, connect with each other and with humans communicating via standard interfaces, and have abilities of storage and processing of data coming from sensors or from the network.

\footnotetext{
* The authors gratefully acknowledge the ministry of agriculture and food which is financing PNAPI through CASDAR (the special appropriation account "Agriculture and Rural Development") under the project number 18 ART 1831 as well as the support and help of Alexandre Dangléant, ITSAP (Technical and Scientific Institute of Beekeeping and Pollination).
} 
The main issues that impact agriculture systems are similar to those presented in manufacturing systems and are primarily related to their sizing, to the understanding of their mechanisms, to the improvement of their productivity and to their performances evaluation. These studies are undertaken by using various techniques of modelling and performances evaluation. In order to be able to implement them, and because of their complexity, it is necessary to use a modelling methodology. This paper presents the first step to analyse and list all the model approaches in function of the time horizons. The proposition is illustrated with a use case on the beekeeping domain. The beekeeping industry faces many problems related to the health of bee colonies concomitant with a general decline in production. Scientific work focused on understanding these phenomena has allowed identifying several causes and establishing concrete elements to guide the decisions of beekeepers [10].

The paper is structured as follows: Section 2 presents a synthetic review of work about smart agriculture and more specifically on beekeeping. Section 3 depicts the approach used to analyse an Agriculture 4.0 system with an application to beekeeping. Finally, Section 4 presents conclusions and perspectives.

\section{Related work}

\subsection{Digital agriculture}

The agriculture will be a very interesting area to exploit the concept of CPS [1]. Indeed, following on from the industrial revolution, the agricultural sector moved from traditional agriculture to the implementation of a full range of modern systems. These systems allow data management of production experiments, fundamental geographic information of farmland, micro-climate information and other data. The same kind of implementation can be used for beekeeping data management.

IoT is another very important paradigm used in agro-industrial and environmental field $[14,15]$. The authors in [14] explain that one of the main requirements for devices used in IoT projects is that they must be energy-efficient. It is a main point on the project, to be able to evaluate the energy impact of the proposed architecture. The authors also explain the interest of Edge Computing in the future of agriculture. The IoT driven by AI-based recommendation model is one of the greatest promise of development [15].

\subsection{Beekeeping and IoT}

To the best of our knowledge, only few papers speak about connected beekeeping. A guideline to move from primitive beekeeping to CPS one is explained in [17]. They converged with the work of [1] which deal with the agriculture area generally.

Some authors proposed architectures with sensors for connected beekeeping. In [7], authors proposed easily replicable technical solutions, based on accurate 
and affordable sensors and a cloud architecture to monitor and follow bees' behavior. For its part, Dogan et al. [9] explain how to build a hive with different sensors and proposed an architecture to exploit them. The figure 1 shows this architecture. They planned to implement an application that allows users to monitor collected data. The information is received by the server in XML or JSON format and visualized and reported by the user application. Users can be notified in real time as well as in the past for specific time period information. They planned to develop a notification mechanism about threatening conditions of bee security or at a time interval determined by the user. A simpler case is shown in [16] with basic Hardware and Software to measure humidity and temperature in a hive. Becher et al. [2] propose a review of the different models. The authors do not use the concepts of IoT and CPS and focus on the behavior of honeybee colonies.

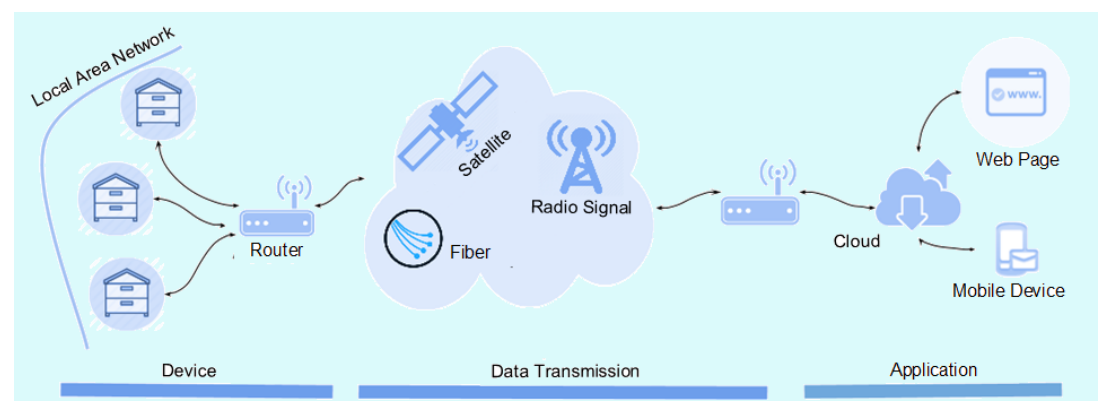

Fig. 1. The general software architecture of the system proposed by [9]

In [8], the most common and popular approaches for solving problems with the bee population by tools of IoT are analysed. These solutions can be improved by using a new type of hardware infrastructure components and modular architecture that are proposed. The proposed solution is directed to small bee producers with the accent on economical and practical benefits. This architecture is network protocol oriented.

Several authors focused on data analysis. In fact, Mikolajuk [11] proposed to use OSEMN process which is a standard and widely accepted model of organization of research in the data science. It can solve the problems with data science/analytic at a large scale. This process is composed by steps to obtain, scrub, explore, model and interpret data from sensors that are located inside and outside hives. The sensors located inside hives collect data about temperature, humidity, weight, noise levels, and more. These data are used to monitor the condition of the bee families. External sensors are situated in different locations in the apiary and collect environmental information (temperature, humidity and $\mathrm{CO} 2$ ) that gives a clear and accurate idea of the particular weather, air pollution, and so on. Cauia et al. [4] proposed to use data to optimize the breeding of the 
honeybees. The data are from genetic area and the observation of the colony. The important question raised by this article is the use of external data to build decision support systems. More recently, text mining and deep learning are used for assisting beekeepers during the process of taking care of their apiary [10].

The literature about beekeeping proposed only applications from microscopic level and with an operational view. The architectures proposed for Agriculture 4.0, the CPS and edge computing concepts could help to build beekeeping architectures. We also need a methodology to know how to use and to help to build an architecture that fulfills all the needs at different levels.

\section{Analysis with a spatio-temporal Matrix}

\subsection{3x3 Matrix}

Several authors propose to start the study of a domain with the goal to design decision support systems by filling a " $3 \times 3$ matrix" composed of two axis: the temporal horizon and the modeling level (table 1). For example, Comelli et al. [6] propose a methodology to evaluate the supply chain. The first step is to analyze the literature by comparing the horizon levels and the different flows. Chabrol et al. [5] propose to couple the time horizons to the modeling approaches to design decision-making aid tools for the hospital systems. In the thesis of Rodier [13], she used this kind of matrix several times to analyse and design decision-making aid tools for different kinds of hospital care units.

Table 1. 3x3 Matrix

\begin{tabular}{l|l|l|l} 
& Macroscopic & Mesoscopic & Microscopic \\
\hline Strategic (year) & & & \\
\hline Tactic (week/month) & & & \\
\hline Operational (day/week) & & & \\
\hline
\end{tabular}

\subsection{Use case on beehives}

This section show the implementation of the spatio-temporal matrix on the beehives domain. To find the different kinds of decisions, we have done the cross-analysis of data of different sources; (i) from the expert of the domain and additionally (ii) from the literature presented in the section 2.The expert, our partner in this project, validate all the process. The matrix is divided in three tables. The macroscopic level (Table 2) corresponds to a territory as the European Union, a country or an area. The mesoscopic level corresponds to the process on an apiary (Table 3). The microscopic level (Table 4) corresponds to activities on a beehive. The strategic decisions consist of sizing the system, the process or the activities. The tactic decisions consist of planning the flow of a system, the process or the activities. The operational decisions consist of evaluating and adapting the system, the process or the activities. 
Table 2. Macroscopic

\begin{tabular}{|l|l|}
\hline & Macroscopic: global view \\
\hline Strategic & $\begin{array}{l}\text { Land (Europe, France, area) } \\
- \text { prediction (health status, production) } \\
- \text { amount of beehives or apiaries } \\
- \text { scalability of the database (infrastructure) } \\
- \text { normalize the logbook of an apiary }\end{array}$ \\
\hline Tactic & $\begin{array}{l}\text { Plan the flow of the system: } \\
- \text { identify the different parameters (user data, cartography of the } \\
\text { resources,...) }\end{array}$ \\
\hline Operational & $\begin{array}{l}\text { Evaluate and adapt the system: } \\
- \text { collect and analyse the data like warning (health,....) } \\
- \text { management of exceptional events (warning) }\end{array}$ \\
\hline
\end{tabular}

Table 3. Mesoscopic

\begin{tabular}{|l|l|}
\hline & Mesoscopic: process view \\
\hline Strategic & $\begin{array}{l}\text { Sizing the process of apiary management: } \\
- \text { define the criteria (resources, kind of bees) } \\
- \text { amount of beehives } \\
- \text { define the type and the amount of feeding } \\
- \text { define the type and the amount of treatment } \\
- \text { write a health risk management }\end{array}$ \\
\hline Tactic & $\begin{array}{l}\text { Plan the process: } \\
- \text { identify the implementation area: } \\
- \text { identify the resources (human and material) } \\
- \text { identify the intervention schedule }\end{array}$ \\
\hline Operational & $\begin{array}{l}\text { Evaluate and adapt the process: } \\
- \text { update the register } \\
- \text { modify the planning } \\
- \text { adjust the amounts according to the needs }\end{array}$ \\
\hline
\end{tabular}


Table 4. Microscopic

\begin{tabular}{|l|l|}
\hline & Microscopic: activities view \\
\hline Strategic & Beehive \\
& $\begin{array}{l}\text { Sizing of the activities: } \\
\text { 1. define the type of the beehive (related to the environment) } \\
\text { 3. define the type and the amount of treatment }\end{array}$ \\
\hline Tactic & $\begin{array}{l}\text { Plan the activities: } \\
\text { 2. identify the amount of feeding }\end{array}$ \\
\hline Operational & $\begin{array}{l}\text { Evaluate and adapt the activities: } \\
\text { 1. number of warms } \\
\text { 2. modify the planning } \\
\text { 3. adjust the amounts according to the needs }\end{array}$ \\
\hline
\end{tabular}

\subsection{ApiSoft: purpose-built application for beekeepers}

In this subsection, we present an example of application on a project. This application called ApiSoft has been developed as part of an internal research project in our laboratory. It is an implementation of part of our architecture. ApiSoft meets operating needs and constraints. It assists the beekeeper in the follow-up of his apiary in order to maximize the harvests by constantly monitoring their apiaries and thus independently communicate the state of the hives. The functionalities of this application are simple to use and considerably facilitate the task of the beekeeper in acquiring data in the field by his tactile input and the saving of his follow-up sheets in a cloud.

The main functionalities are represented in the figure 2 with an Use Case diagram. The figure 2 also shows an extract of the ER model represented by a class diagram. A client is installed on the users' smartphone and all the services are accessible via internet. For example, the alert management service is centralized on the cloud. It analyzes the data, makes decisions and it notifies if necessary. The application ApiSoft is able to extract relevant information by processing data from different sources like social media, web, data provided by experts and this application is embedded on the beekeepers' smartphone. Once data are collected, ApiSoft can send alerts, information and pieces of advice about the state of apiaries to all subscribers according to their specific interests.

The figure 3 presents the interface where the beekeeper can collect data about a beehive (ruche in French) after selecting the apiary (Rucher in French). The interface is also connected to external data like the weather. The beekeeper can add other kinds of data: before opening the beehive (Avant ouverture de la ruche) and after opening the beehive (Après ouverture de la ruche). 


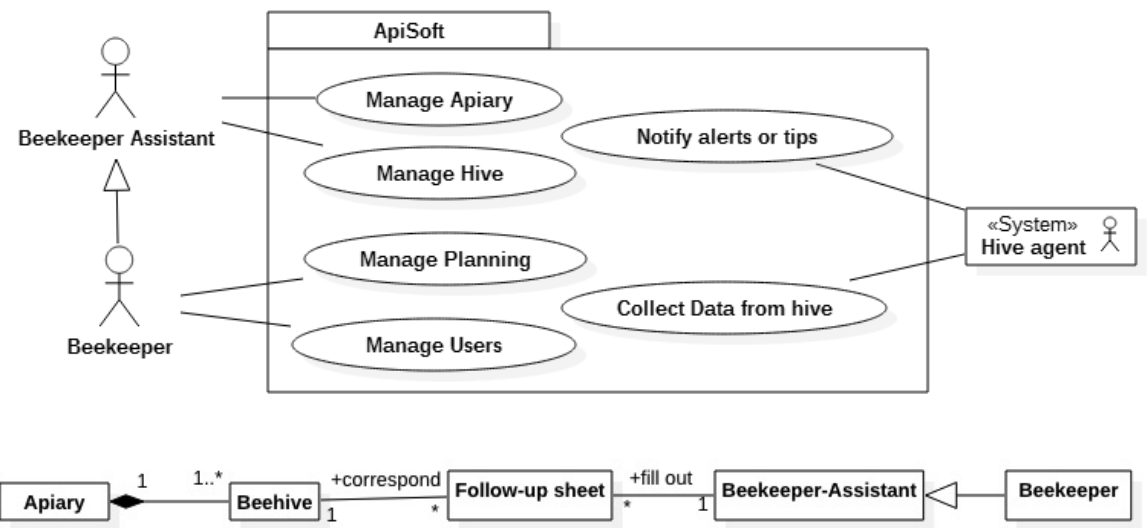

Fig. 2. Two extracts of UML diagrams from the specification

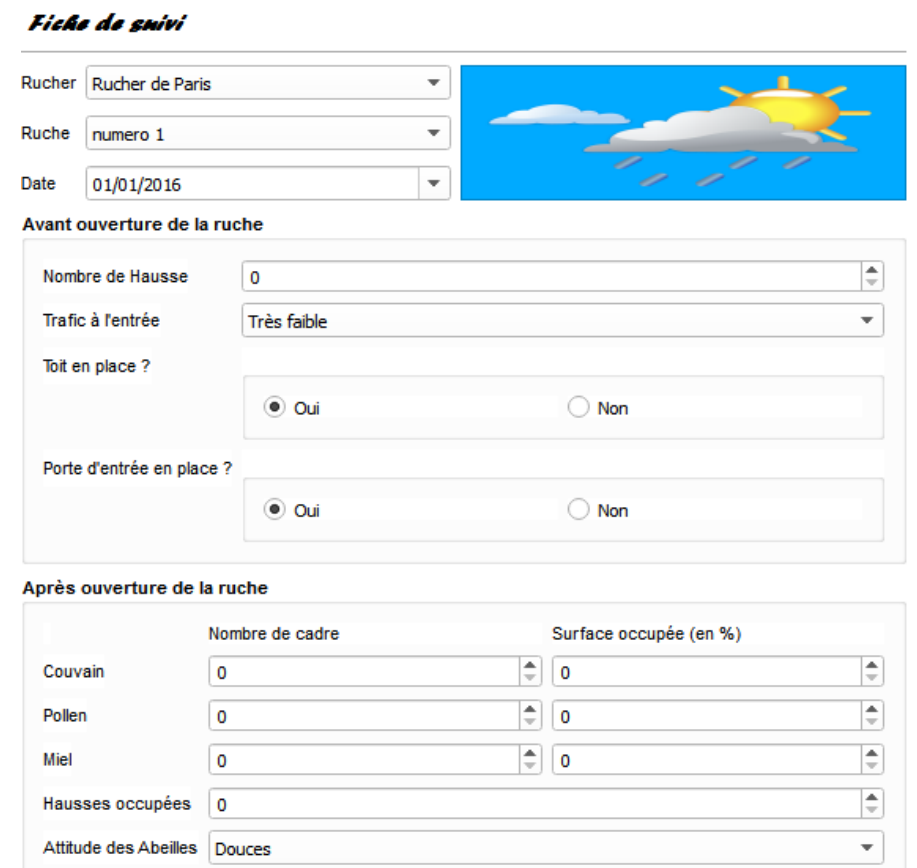

Fig. 3. Screenshot of the ApiSoft application: interface to collect data for beehives 
The figure 4 shows the data for all the beehives (ruche) of an apiary (Rucher). Different data are shown like the Traffic, the attitude, if the queen (Reine) are marked, if the beekeeper saw some symptoms and if the beehive received a treatment (Traitement).

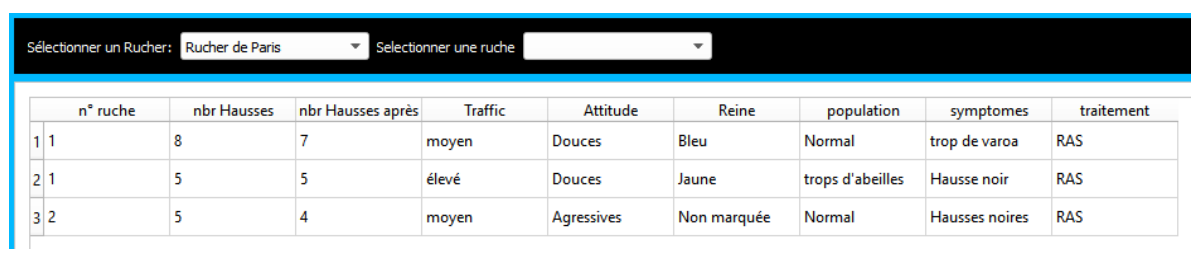

Fig. 4. Screenshot of the ApiSoft application: list of data for beehives

The intelligent system architecture is based on the collection of heterogeneous data. The data collected here allows designing decision making aid tools to help beekeepers to take care of their beehives. In fact, the data collected are automatically analysed by the application. The decision that can be made corresponds to the last two lines of the table 4 . Indeed, it fits with the microscopic level (decision on beehive) and the time horizons are tactical and operational.

\section{Conclusion}

This paper presented a part of a general approach to design an intelligent system architecture with an application on smart beehives. More precisely, it proposed a new methodology in order to design decision making tools for smart agriculture. This is the first step of a global methodology which could model, evaluate the performance, manage, supervise digitalized agriculture systems.

All the modeling approaches are added in a spatio-temporal matrix with the time and the geographical horizons.

A use case on the digitalized beekeeping domain is shown. One example of application is depicted for a tactical decision in the apiary.

The next step of this work will be to continue the development of a global methodology for tackle issues related to smart agriculture. The development of a global architecture linked to the methodology to register all the data at different levels is also a very import perspective. This architecture would be based on Industry 4.0 and fog computing (Edge Computing). Indeed, we want to have databases with different hierarchical levels. Edge Computing and/or Fog Computing seem to be a good solution and we could use architectures proposed by these concepts [12]. 


\section{References}

1. Ahmed, S.H., Kim, G., Kim, D.: Cyber physical system: Architecture, applications and research challenges. In: 2013 IFIP Wireless Days (WD). pp. 1-5 (Nov 2013). https://doi.org/10.1109/WD.2013.6686528

2. Becher, M.A., Osborne, J.L., Thorbek, P., Kennedy, P.J., Grimm, V.: Review: Towards a systems approach for understanding honeybee decline: a stocktaking and synthesis of existing models. Journal of Applied Ecology 50(4), 868-880 (2013). https://doi.org/10.1111/1365-2664.12112, https://besjournals.onlinelibrary.wiley.com/doi/abs/10.1111/1365-2664.12112

3. Cardin, O.: Classification of cyber-physical production systems applications: Proposition of an analysis framework. Computers in Industry 104, 11 - 21 (2019). https://doi.org/https://doi.org/10.1016/j.compind.2018.10.002, http://www.sciencedirect.com/science/article/pii/S0166361517306231

4. Cauia, E., Siceanu, A., Sapcaliu, A., Magdici, M., Chirila, A., Cauia, D.: The evaluation of honeybee colonies, using a database with application on honeybee breeding programs. In: The proceedings of 41th Apimondia Congress, Montpelier, 2009 (2009)

5. Chabrol, M., Gourgand, M., Rodier, S.: A modeling methodology and its application to the design of decision-making aid tools dedicated to the hospital systems. In: RCIS'08:International Conference on Research Challenges in Information, 2008 (2008)

6. Comelli, M., Féniès, P., Tchernev, N.: A combined financial and physical flows evaluation for logistic process and tactical production planning: Application in a company supply chain. International Journal of Production Economics 112(1), 77 - 95 (2008). https://doi.org/http://dx.doi.org/10.1016/j.ijpe.2007.01.012, special Section on Recent Developments in the Design, Control, Planning and Scheduling of Productive Systems

7. Debauche, O., Moulat, M.E., Mahmoudi, S., Boukraa, S., Manneback, P., Lebeau, F.: Web monitoring of bee health for researchers and beekeepers based on the internet of things. Procedia Computer Science 130, 991 - 998 (2018). https://doi.org/https://doi.org/10.1016/j.procs.2018.04.103, http://www.sciencedirect.com/science/article/pii/S1877050918304654, the 9th International Conference on Ambient Systems, Networks and Technologies (ANT 2018) / The 8th International Conference on Sustainable Energy Information Technology (SEIT-2018) / Affiliated Workshops

8. Dineva, K., Atanasova, T.: Model of modular iot-based bee-keeping system. In: European Simulation and Modelling Conference ESM. pp. 404-406 (2017)

9. Dogan, S., Akbal, E., Koca, G.O., Balta, A.: Design of a remote controlled beehive for improving efficiency of beekeeping activities. In: 8th International advanced technologies symposium (2017)

10. Latioui, Z.E., Bougueroua, L., Moretto, A.: Social media chatbot system - beekeeping case study. In: Madureira, A.M., Abraham, A., Gandhi, N., Varela, M.L. (eds.) Hybrid Intelligent Systems. pp. 302-310. Springer International Publishing, Cham (2020)

11. Mikolajuk, Z.: A computer-based knowledge delivery system for rural communitiesa case study using beekeeping. In: Proceedings of the Knowledge Management International Conference and Exhibition, Kuala Lumpur, Malaysia (2006)

12. Mouradian, C., Naboulsi, D., Yangui, S., Glitho, R.H., Morrow, M.J., Polakos, P.A.: A comprehensive survey on fog computing: State-of-the-art and research 
challenges. IEEE Communications Surveys Tutorials 20(1), 416-464 (Firstquarter 2018). https://doi.org/10.1109/COMST.2017.2771153

13. Rodier, S.: An attempt to unify and solve the questions of modeling and optimization within the hospital systems. Application to the New Estaing Hospital. Theses, Université Blaise Pascal - Clermont-Ferrand II (Jul 2010), https://tel.archivesouvertes.fr/tel-00719096

14. Talavera, J.M., Tobón, L.E., Gómez, J.A., Culman, M.A., Aranda, J.M., Parra, D.T., Quiroz, L.A., Hoyos, A., Garreta, L.E.: Review of iot applications in agroindustrial and environmental fields. Computers and Electronics in Agriculture 142, 283 - 297 (2017). https://doi.org/https://doi.org/10.1016/j.compag.2017.09.015, http://www.sciencedirect.com/science/article/pii/S0168169917304155

15. Vincent, D.R., Deepa, N., Elavarasan, D., Srinivasan, K., Chauhdary, S.H., Iwendi, C.: Sensors driven ai-based agriculture recommendation model for assessing land suitability. Sensors 19(17), 3667 (Aug 2019). https://doi.org/10.3390/s19173667, http://dx.doi.org/10.3390/s19173667

16. Vornicu, O.C.: Monitorizing system of bee families activity. In: 7th International Conference on Development And Application Systems (2004)

17. Zogović, N., Mladenović, M., Rašić, S.: From primitive to cyber-physical beekeeping. In: 7th International Conference on Information Society and Technology ICIST 2017 (2017) 